\title{
Evaluation of the Radiated Power from Near-field Measurements Acquired via the Planar Wide-mesh Scanning
}

UDK 621.396 .677

IFAC 4.3 .2

Preliminary communication

\begin{abstract}
A full procedure is developed in this paper for evaluating the power radiated by an antenna under test from a nonredundant number of near-field measurements collected by the innovative planar wide-mesh scanning. It can be applied for the antenna directivity evaluation whenever the power radiated by the antenna in the backward half-space is negligible. Such a procedure makes use of a closed form formula for computing the total radiated power from the knowledge of the radiation intensity samples on the far-field sphere. These samples are determined via a probe compensated near-field - far-field transformation. An optimal sampling interpolation formula is also used for their evaluation. The effectiveness of the proposed procedure is assessed by numerical simulations.
\end{abstract}

Key words: directivity evaluation, NF-FF transformations, nonredundant sampling representations of electromagnetic fields, planar wide-mesh scanning

\section{INTRODUCTION}

As well-known, the directivity function of a transmitting system describes the variation of the radiation intensity, which is the power radiated per unit solid angle, with direction in space. Therefore, its evaluation gives information about the capacity of the antenna to concentrate the radiation in a given direction. This is very important when using the radiating structure for specialized and high-performance communication links and radar systems.

According to its definition, the crucial point in the directivity evaluation is represented by the computation of the total radiated power. It requires the integration of the radiation intensity over the whole solid angle of $4 \pi$. Unfortunately, for most practical antennas, the mathematical expression of the radiation intensity function (if available) is so complex that the integration cannot be performed analytically. Numerical methods taking advantage of modern computational facilities are then necessary, but they become time consuming when the computation of the radiation intensity is onerous, as in the case of radiating systems very large in terms of wavelengths.

Most solutions available in literature are approximate and not applicable to any kind of antenna under test (AUT) (see references $[1,11]$ for a se- lected bibliography). A formula for determining the total radiated power from the knowledge of the radiation intensity in a fixed number of points on the far-field sphere was obtained by Dich in [12]. It is based on the theory of spherical wave expansion of the electromagnetic (EM) field and on the results in [13]. It allows the directivity estimation from simulated or measured data. A simple, fast and accurate sampling interpolation (SI) formula was proposed in [14]. It has the same advantages of the Dich's solution, but requires a lower number of data without loosing the accuracy. The derivation of such a formula is based on the spatial bandlimitation property [15] and nonredundant sampling representations [16] of the EM fields radiated by a transmitting antenna, so that a sampling expansion of the radiation intensity is adopted to reduce the surface integral in summations. As a consequence, such a formula depends only on the sizes of the AUT and gives an efficient way for the directivity computation from simulated or measured data.

If the radiation pattern is not available in analytical form, it can be obtained by means of measurements over a spherical surface in the AUT far-field (FF) region. In order to perform accurate antenna measurements, the influence of uncontrollable environment conditions must be reduced as 
much as possible by carrying out the measurements in anechoic chambers. Unfortunately, when dealing with electrically large antennas, the FF distance requirements cannot be satisfied, so that only near-field (NF) measurements can be performed and the FF data must be recovered via NF-FF transformation techniques. Among them, those employing planar scannings are well-suited for directive antennas which radiate pencil beam patterns. In fact, for pencil beam antennas, the power radiated in the backward half-space $(z<0)$ is negligible and the total radiated power coincides practically with that radiated in the forward half-space.

A fast and accurate NF-FF transformation technique using the innovative planar wide-mesh scanning (PWMS) has been proposed in [17] by properly applying the nonredundant sampling representations [16]. In such a scanning, the linear spacing between two consecutive lines (along $x$ or $y$ ) of the scanning grid increases when their distance from the center of the measurement plane increases (see Figure 1). This NF-FF transformation technique makes use of a two-dimensional optimal sampling interpolation (OSI) formula, which allows the effective reconstruction of the NF data required by the classical NF-FF transformation with plane-rectangular scanning [18] from the knowledge of those collected via PWMS. It must be stressed that this innovative scanning grid allows one to reduce significantly the amount of needed NF data without losing the accuracy and computational efficiency of the classical approach.

According to the above considerations, the goal of this paper is to provide a full procedure for determining the directivity of an AUT from NF data

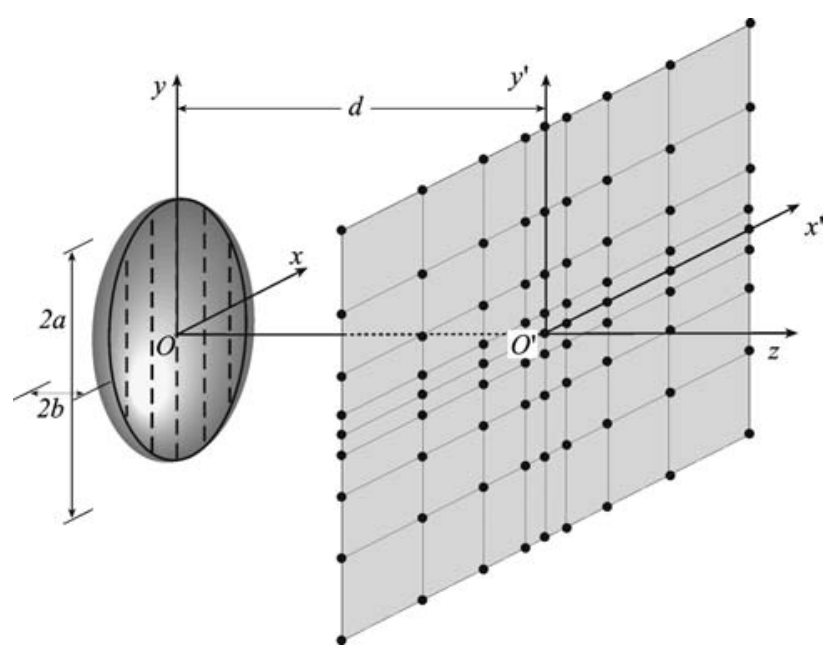

Fig. 1 Planar wide-mesh scanning acquired by means of a PWMS facility. Such a procedure is logically divided into three steps: a) acquisition of the probe voltage samples; b) evaluation of the radiation intensity samples on the FF sphere via the NF-FF transformation with PWMS [17]; c) computation of the AUT directivity by using the proposed SI formula. Note that the step b) is split in two substeps. In the former, as result of the FFT algorithm employed in the NF-FF transformation, we get FF samples uniformly spaced in $k_{x}=\beta \sin \Theta \cos \Phi$ and $k_{y}=\beta \sin \Theta \sin \Phi, \beta$ being the wavenumber. In the latter, a two-dimensional OSI expansion of central type is properly used to reconstruct the radiation intensity data at the sampling points (uniformly spaced in $\Theta$ and $\Phi)$ required by the SI formula.

\section{EVALUATION OF THE RADIATED POWER FROM PLANE-RECTANGULAR NF DATA}

The aim of this section is to provide a full procedure for determining the AUT directivity from NF data acquired on a plane at distance $d$ via the plane-rectangular scanning. As a matter of fact, when considering pencil beam antennas, the power radiated in the half-space $z<0$ is negligible and the total radiated power $P_{\text {tot }}$ coincides substantially with that radiated in the forward half-space. Accordingly,

$$
P_{\text {tot }}=\int_{0}^{\frac{\pi}{2}} \int_{-\pi}^{\pi} U(\Theta, \Phi) \sin \Theta \mathrm{d} \Phi \mathrm{d} \Theta
$$

The radiation intensity $U(\Theta, \Phi)$ can be evaluated according to the relation:

$$
U(\Theta, \Phi)=\frac{R^{2}}{2 \zeta}\left[\left|E_{\Theta}(\Theta, \Phi)\right|^{2}+\left|E_{\Phi}(\Theta, \Phi)\right|^{2}\right]
$$

wherein $E_{\Theta}, E_{\Phi}$ are the FF components of the electric field, $R$ is the distance and $\zeta$ is the free-space impedance.

An efficient SI formula for determining $P_{\text {tot }}$ is described in the following. Its derivation is based on the aforementioned nonredundant sampling representations [16], so that a sampling expansion is adopted for reducing the surface integral in summations. Such an expansion is formally the same as that for representing the field. In fact, as a straightforward consequence of the frequency convolution theorem, the radiation intensity is an almost bandlimited function characterized by a bandwidth which is the double of the corresponding field bandwidth. Therefore, a sampling representa- 
tion can be still used, provided that the sampling spacings are halved.

According to the theoretical results in [16], let us consider the AUT as enclosed in the small convex surface $\Sigma$ with rotational symmetry containing it and let us introduce the »reduced electric field «

$$
\underline{F}(\xi)=\underline{E}(\xi) \mathrm{e}^{\mathrm{j} \gamma(\xi)},
$$

where the phase function $\gamma(\xi)$ and the optimal parameter $\xi$ describing a curve on the observation surface must be determined. When $F$ is approximated by a bandlimited function, the corresponding bandlimitation error becomes negligible as the spatial bandwidth exceeds a critical value $W_{\xi}$ [16]. Therefore, such an error can be effectively controlled by choosing a bandwidth equal to $\chi^{\prime} W_{\xi}$, where $\chi^{\prime}$ is an enlargement factor slightly greater than unity for electrically large antennas.

In the considered case, the observation surface is the FF sphere which can be described by meridians and parallels. According to the abovementioned results [16], the samples number on a meridian depends only on the maximum dimension $2 a$
$\Theta_{n}=n \Delta \Theta=\frac{2 \pi n}{2 N+1} ; \quad N=2\left[\operatorname{Int}\left(\chi^{\prime} \beta a\right)+1\right]$

$\Phi_{m, n}=m \Delta \Phi_{n}=\frac{2 m \pi}{2 M_{n}+1} ; \quad M_{n}=2\left[\operatorname{Int}\left(\chi^{*} \beta \rho_{\max } \sin \Theta_{n}\right)+1\right]$

$\chi^{*}=1+\left(\chi^{\prime}-1\right)\left[\sin \Theta_{n}\right]^{-2 / 3}$.

$\operatorname{Int}[x]$ gives the integer part of $x$, and $D_{J}(\cdot)$ is the Dirichlet function given by

$$
D_{J}(x)=\frac{\sin \left((2 J+1) \frac{x}{2}\right)}{(2 J+1) \sin \left(\frac{x}{2}\right)} .
$$

The variation of the azimuthal enlargement bandwidth factor $\chi^{*}$ with $\Theta$ in (9) is required in order to ensure a bandlimitation error constant with respect to $\Theta$.

It is worthy to note that, in here considered case of pencil beam antennas, $\rho_{\max }=a$ and the expansion (6) is the truncated version of that proposed in [14]. By substituting (6) into (1) and inverting the integration and summation order, it results:

$$
P_{\text {tot }}=\sum_{n=\frac{N}{2}}^{\frac{N}{2}} \sum_{m=-M_{n}}^{M_{n}} U\left(\Theta_{n}, \Phi_{m, n}\right) \int_{0}^{\frac{\pi}{2}} \int_{-\pi}^{\pi} D_{N}\left(\Theta-\Theta_{n}\right) D_{M_{n}}\left(\Phi-\Phi_{m, n}\right) \sin \Theta \mathrm{d} \Phi \mathrm{d} \Theta .
$$

of $\Sigma$, whereas the sampling rate on a parallel is related to its position and the maximum transverse dimension $2 \rho_{\max }$ of $\Sigma$, i.e.,

\section{- meridians}

$$
\xi=\Theta ; \quad W_{\Theta}=\beta a ; \quad \gamma=\text { const }
$$

- parallels

$$
\xi=\Phi ; \quad W_{\Phi}=\beta_{\rho \max } \sin \Theta ; \quad \gamma=\text { const. }
$$

As a consequence, the following cardinal series (CS) expansion can be properly employed to represent the radiation intensity:

$$
\begin{gathered}
U(\Theta, \Phi)= \\
=\sum_{n=-\frac{N}{2}}^{\frac{N}{2}} \sum_{m=-M_{n}}^{M_{n}} U\left(\Theta_{n}, \Phi_{m-n}\right) D_{N}\left(\Theta-\Theta_{n}\right) D_{M_{n}}\left(\Phi-\Phi_{m, n}\right)
\end{gathered}
$$

where
Now, by taking into account that

$$
\int_{-\pi}^{\pi} D_{M_{n}}\left(\Phi-\Phi_{m, n}\right) \mathrm{d} \Phi=\frac{2 \pi}{2 M_{n}+1}
$$

we get

$$
P_{\text {tot }}=\sum_{n=-\frac{N}{2}}^{\frac{N}{2}} \frac{2 \pi}{2 M_{n}+1} I_{n} \sum_{m=-M_{n}}^{M_{n}} U\left(\Theta_{n}, \Phi_{m, n}\right)
$$

where

$$
I_{n}=\int_{0}^{\frac{\pi}{2}} D_{N}\left(\Theta-\Theta_{n}\right) \sin \Theta \mathrm{d} \Theta
$$

After some straightforward analytical manipulations, the evaluation of such an integral furnishes:

$$
I_{n}=\frac{1}{2 N+1}\left[A_{n} \cos \Theta_{n}-\left(B_{n}-C_{n}\right) \sin \Theta_{n}\right]
$$


where

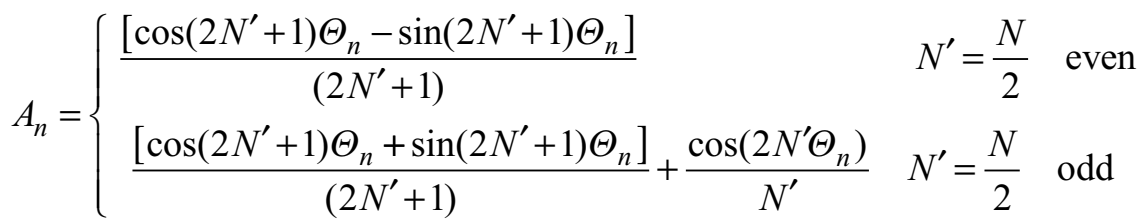

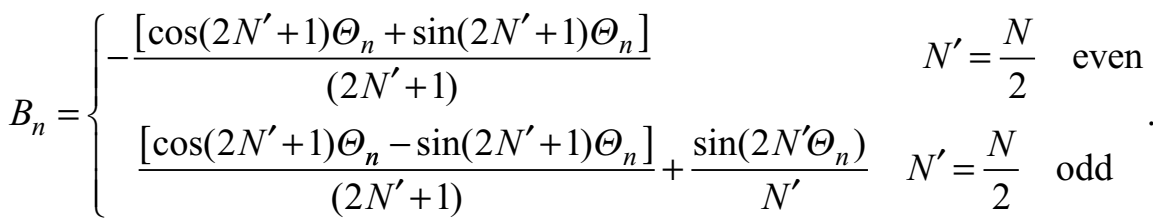

$$
\begin{aligned}
& C_{n}=\frac{\pi}{2}+\sum_{k=1}^{N} \frac{2}{k}\left[\left(1-\cos \frac{k \pi}{2}\right) \sin k \Theta_{n}+\sin \frac{k \pi}{2} \cos k \Theta_{n}\right] \text {. }
\end{aligned}
$$

When the radiation intensity samples to be used in the SI formula (13) must be recovered from the $\mathrm{NF}$ data acquired via a plane-rectangular scanning, as already stated, a proper OSI expansion must be employed to determine the radiation intensity data at the required sampling points.

$$
E_{\Phi}(\Theta, \Phi)=\frac{I_{H} E_{\Theta_{V}}^{\prime}(\Theta,-\Phi)-I_{V} E_{\Theta_{H}}^{\prime}(\Theta,-\Phi)}{\Delta}
$$

where

$$
\Delta=E_{\Theta_{H}}^{\prime}(\Theta,-\Phi) E_{\Phi_{V}}^{\prime}(\Theta,-\Phi)-E_{\Theta_{V}}^{\prime}(\Theta,-\Phi) E_{\Phi_{H}}^{\prime}(\Theta,-\Phi)
$$

$$
I_{V, H}=A \cos \Theta \mathrm{e}^{j \beta d \cos \Theta} \int_{-\infty}^{+\infty} \int_{-\infty}^{+\infty} V_{V, H}(x, y) \mathrm{e}^{\mathrm{j} \beta x \sin \Theta \cos \Phi} \mathrm{e}^{\mathrm{j} \beta y \sin \Theta \sin \Phi} \mathrm{d} x \mathrm{~d} y
$$

$A$ being a constant.

For reader's convenience, the key steps of the standard probe compensated NF-FF transformation with plane-rectangular scanning [18] are reported in the following. In such a scanning, the sample spacings of the NF data are

$$
\Delta x \leq \frac{\lambda}{2}, \quad \Delta y \leq \frac{\lambda}{2}
$$

$\lambda$ being the wavelength. According to such a technique, the FF components $E_{\Theta, \Phi}(\Theta, \Phi)$ of the field radiated by the AUT are related to: i) the Fourier transforms $I_{V}$ and $I_{H}$ of the output voltages $V_{V}$ and $V_{H}$ of the probe for two independent sets of measurements (the probe is rotated by $90^{\circ}$ in the second set); ii) the FF components $E_{\Theta_{V}}^{\prime}, E_{\Phi_{V}}^{\prime}$ and $E_{\Theta_{H}}^{\prime}$, $E_{\Phi_{H}}^{\prime}$ radiated by the probe and the rotated probe, when used as transmitting antennas. The key relations are:

$$
E_{\Theta}(\Theta, \Phi)=\frac{I_{H} E_{\Phi_{V}}^{\prime}(\Theta,-\Phi)-I_{V} E_{\Phi_{H}}^{\prime}(\Theta,-\Phi)}{\Delta}
$$

Now, as result of the FFT algorithm used in the plane-rectangular NF-FF transformation, the Fourier transforms of the probe voltages and, as a consequence, the AUT far-field components are known at the values of $k_{x}$ and $k_{y}$ specified by

$$
\frac{2 \pi n}{N_{x} \Delta x} \text { and } \frac{2 \pi m}{N_{y} \Delta y},
$$

where $N_{x}$ and $N_{y}$ are the numbers of the measurement points along $x$ and $y$.

A two-dimensional OSI scheme can be properly adopted to get $E_{\Theta, \Phi}$ at a given direction $\Theta, \Phi$. Its mathematical justification relies on the fact that the AUT far field is related to the Fourier transform of the probe voltages. Therefore, if these voltages are practically negligible for $|x|>L_{x}$ and $|y|>L_{y}$, as a consequence of the Nyquist sampling theorem, $\tilde{I}_{V, H}=I_{V, H} \mathrm{e}^{-\mathrm{j} \beta \cos \Theta}$ can be reconstructed from its samples at a rectangular lattice of points separated by the spacings

$$
\Delta k_{x} \leq \frac{\pi}{L_{x}} \quad \text { and } \quad \Delta k_{y} \leq \frac{\pi}{L_{y}} .
$$


Accordingly, the following OSI expansion can be employed to reconstruct $I_{V, H}$ at the values of $k_{x}$ and $k_{y}$ corresponding to the direction $\Theta, \Phi$ :

$$
\begin{gathered}
I_{V, H}\left(k_{x}, k_{y}\right)= \\
=\mathrm{e}^{\mathrm{j} \beta d \cos \Theta} \sum_{n=n_{0}-q+1}^{n_{0}+q}\left\{\Psi\left(k_{x}-k_{x_{n}}\right) \operatorname{sinc}\left(\pi \frac{\left(k_{x}-k_{x_{n}}\right)}{\Delta k_{x}}\right) .\right. \\
\left.\cdot \sum_{m=m_{0}-p+1}^{m_{0}+p} \tilde{I}_{V, H}\left(k_{x_{n}}, k_{y_{m}}\right) \Psi\left(k_{y}-k_{y_{m}}\right) \operatorname{sinc}\left(\pi \frac{\left(k_{y}-k_{y_{n}}\right)}{\Delta k_{y}}\right)\right\}
\end{gathered}
$$

where $\operatorname{sinc}(\tau)$ is the $\sin (\tau) / \tau$ function, $2 q \times 2 p$ is the number of retained samples, $n_{0}$ and $m_{0}$ are the indices of the sample nearest on the left to the output point,

$$
\begin{aligned}
& k_{x_{n}}=n \Delta k_{x}=\frac{2 \pi n}{N_{X} \Delta x} \\
& k_{y_{m}}=m \Delta k_{y}=\frac{2 \pi m}{N_{Y} \Delta y}
\end{aligned}
$$

$N_{X} N_{Y}>N_{x} N_{y}$ being the overall number of the NF data (comprehensive of those employed for the "zero-filling «). Moreover,

$$
\Psi(\tau)=\cosh \frac{\pi \mu s \sqrt{1-\left(\frac{\tau}{\tau_{0}}\right)}}{\cosh (\pi \mu s)}
$$

is the Knab's sampling window function [19] in which $\tau_{0}=s \Delta \tau$ and $\mu=1-1 / \chi, \chi>1$ being an oversampling factor which allows the control of the truncation error when using an OSI algorithm. Note that $\tau_{0}=q \Delta k_{x}$ and $\chi=N_{X} / N_{x}$ in the interpolation along $k_{x}$, whereas $\tau_{0}=p \Delta k_{y}$ and $\chi=N_{Y} / N_{y}$ in the interpolation along $k_{y}$.

\section{FROM PWMS SAMPLES TO PLANE-RECTANGULAR NF DATA}

The results of the previous section can be properly applied for evaluating the power radiated by an AUT when the NF measurements are acquired by means of the PWMS [17]. Let us consider a non directive probe scanning a plane located at a distance $d$ from the AUT center, that is assumed as origin of the cartesian coordinate system $x, y, z$ (see Figure 1). For such a probe, the voltage has the same effective spatial bandwidth of the field radiated by the AUT. This last is assumed quasiplanar, so that an effective source modelling can be obtained by choosing the surface $\Sigma$ (enclosing it) coincident with the smallest oblate ellipsoid with major and minor semi-axes equal to $a$ and $b$ (Figure 1). Accordingly, it is convenient to introduce the "reduced voltage « $\tilde{V}(\xi)=V(\xi) \mathrm{e}^{\mathrm{j} \gamma(\xi)}$, $V(\xi)$ being the measured voltage.

If the observation curve is a radial line, as the $x^{\prime}\left(\right.$ or $\left.y^{\prime}\right)$ axis, by adopting $W_{\xi}=\frac{\beta \ell^{\prime}}{2 \pi}\left(\ell^{\prime}\right.$ is the length of the ellipse obtained as intersection curve between the meridian plane through the observation point $P(\xi)$ and $\Sigma$ ) it results [16]:

$$
\begin{gathered}
\gamma=\beta a\left[v \sqrt{\frac{v^{2}-1}{v^{2}-\varepsilon^{2}}}-E\left(\cos ^{-1} \sqrt{\frac{1-\varepsilon^{2}}{v^{2}-\varepsilon^{2}}} \mid \varepsilon^{2}\right)\right] \\
\xi=\frac{\pi}{2}\left[\frac{E\left(\sin ^{-1} u \mid \varepsilon^{2}\right)}{E\left(\frac{\pi}{2} \mid \varepsilon^{2}\right)}\right]
\end{gathered}
$$

where $E(\cdot \mid \cdot)$ is the elliptic integral of second kind, $\varepsilon=\frac{f}{a}$ is the ellipsoid eccentricity, and $u=\frac{r_{1}-r_{2}}{2 f}, v=\frac{r_{1}+r_{2}}{2 a}$ are the elliptic coordinates, $r_{1,2}$ being the distances from $P$ to the foci and $2 f$ the focal distance.

In order to factorize the two-dimensional interpolation scheme into one-dimensional OSI expansions along lines, it is mandatory to adopt the same parameter $\xi(\eta)$ given by (27) for describing all lines parallel to the $x^{\prime}\left(y^{\prime}\right)$ axis. As a consequence, the samples spacing on them is the same of the $x^{\prime}$ $\left(y^{\prime}\right)$ axis (see Figure 1). This corresponds to use a parameter that does not make constant the local bandwidth. Since this last is always less or equal than $W_{\xi}$, no further representation error is introduced. The so obtained grid has meshes wider and wider when going away from the center. For what concerns the phase function $\gamma$, it can be shown that expression (26) is still valid. The following OSI expansion can be used to interpolate the reduced voltage samples:

$$
\tilde{V}(\xi, \eta)=\sum_{n=n_{0}-q+1}^{n_{0}+q}\left\{\Omega_{M}\left(\xi-\xi_{n}\right) D_{M^{\prime \prime}}\left(\xi-\xi_{n}\right) \sum_{m=m_{0}-p+1}^{m_{0}+p} \tilde{V}\left(\xi_{n}, \eta_{m}\right) \Omega_{M}\left(\eta-\eta_{m}\right) D_{M^{\prime \prime}}\left(\eta-\eta_{m}\right)\right\}
$$


where

$\tilde{V}\left(\xi_{n}, \eta_{m}\right)$ are the samples,

$n_{0}=\operatorname{Int}\left(\frac{\xi}{\Delta \xi}\right), m_{0}=\operatorname{Int}\left(\frac{\eta}{\Delta \eta}\right)$ are the indexes of

the sample nearest to the output point, $2 q \times 2 p$ is the number of retained samples and

$$
\begin{aligned}
& \eta_{m}=m \Delta \eta ; \quad \xi_{n}=n \Delta \xi ; \quad \Delta \eta=\Delta \xi=\frac{2 \pi}{2 M^{\prime \prime}+1} \\
& M^{\prime \prime}=\operatorname{Int}\left(\chi M^{\prime}\right)+1 ; \quad M^{\prime}=\operatorname{Int}\left(\chi^{\prime} W_{\xi}\right)+1 .
\end{aligned}
$$

Moreover,

$$
\Omega_{M}(x)=\frac{T_{M}\left[2 \cos ^{2} \frac{\frac{x}{2}}{\cos ^{2}\left(\frac{x_{0}}{2}\right)-1}\right]}{T_{M}\left[\frac{2}{\cos ^{2}\left(\frac{x_{0}}{2}\right)-1}\right]}
$$

is the Tschebyscheff Sampling function [16], wherein $T_{M}(\cdot)$ is the Tschebyscheff polynomial of degree $M=M^{\prime \prime}-M^{\prime}$, and $x_{0}=q \Delta \xi$ or $p \Delta \eta$.

The OSI formula (28) can be employed to recover the voltage at any point of the measurement plane and, in particular, at those required by the classical probe-compensated NF-FF transformation with plane-rectangular scanning [18].

\section{NUMERICAL TESTS}

Two numerical tests are reported in the following to assess the effectiveness of the proposed technique. The former example refers to a uniform planar circular array (Figure 1) with radius equal to $15.6 \lambda$. Its elements, elementary Huygens sources linearly polarized along the $y$ axis, are radially and azimuthally spaced of $0.6 \lambda$. The measurement plane is $10 \lambda$ away from the AUT center and the samples lie in a $80 \lambda \times 80 \lambda$ square, apart from the guard samples. The array has been modelled by an oblate ellipsoid with major and minor semi-axes equal to $16 \lambda$ and $2 \lambda$. An open-ended WR-90 rectangular waveguide, operating at $10 \mathrm{GHz}$, is chosen as probe. It is worth noting that $p=q=6$ and $\chi=\chi^{\prime}=1.20$ have been used for reconstructing the plane-rectangular NF data required by the NF-FF transformation [18]. The exact and reconstructed E-plane patterns are reported in Figure 2.

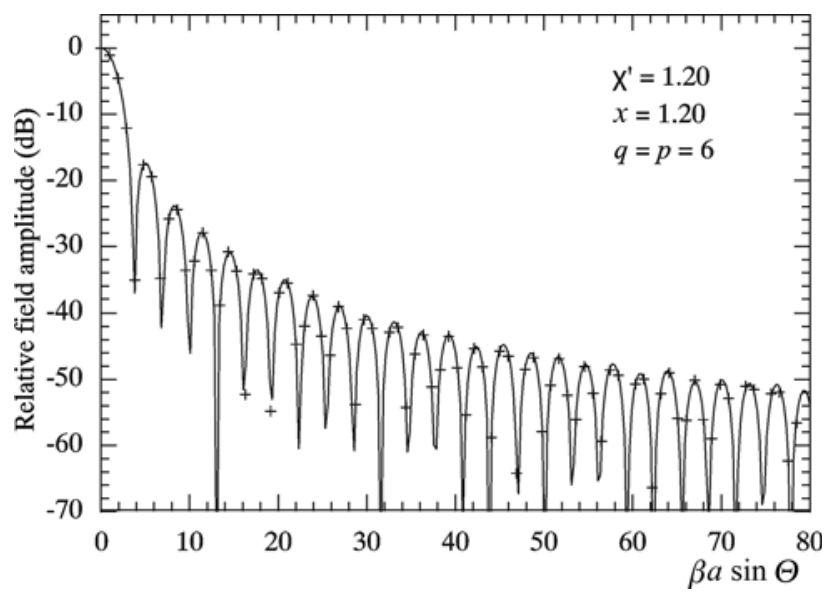

Fig. 2 E-plane pattern $\left(\Phi=90^{\circ}\right)$. Solid line: exact. Crosses: reconstructed from PWMS data

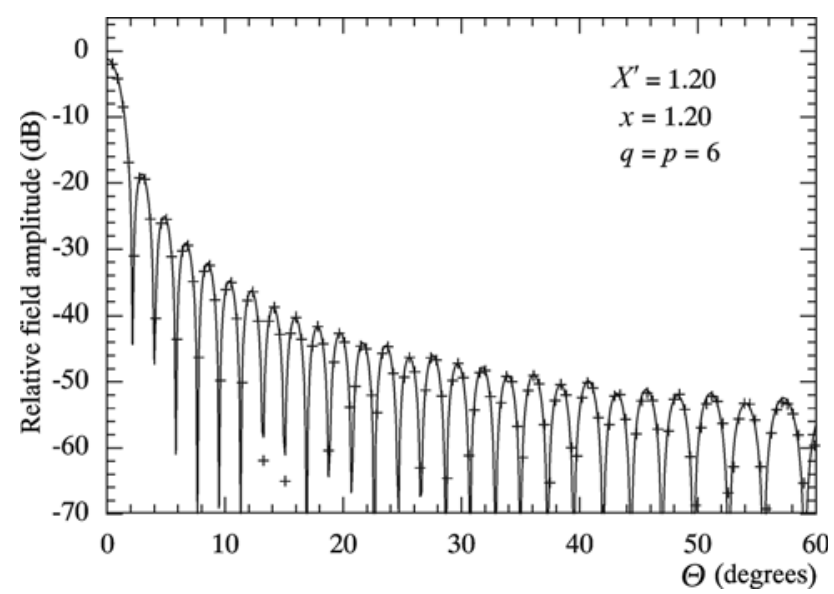

Fig. 3 Amplitude of the FF component $E_{\Theta}$ at $\Phi=60^{\circ}$. Solid line: exact. Crosses: reconstructed from PWMS data

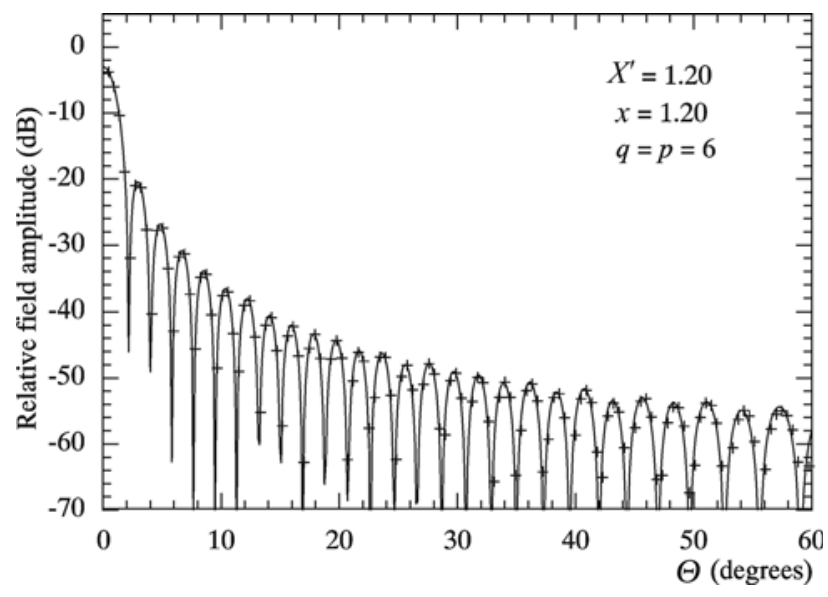

Fig. 4 Amplitude of the FF component $E_{\Theta}$ at $\Phi=45^{\circ}$. Solid line: exact. Crosses: reconstructed from PWMS data 
In order to show the effectiveness of the FF interpolation, the reconstructions of the FF component $E_{\Theta}$ in the cut planes at $\Phi=60^{\circ}$ and $\Phi=45^{\circ}$ are reported in Figure 3 and Figure 4, respectively. As can be seen, the recovery is very accurate. Note that $p=q=6$ and $\chi=512 / 250=2.048$ have been assumed in the FF interpolation.

The value of the total power radiated in the forward half-space, resulting from the application of (13) to the FF data reconstructed via the NF-FF transformation and normalized to the maximum value of the radiation intensity, is compared in Table 1 with those obtained by other techniques. As can be seen, the results assess the effectiveness of the procedure.

Table 1

\begin{tabular}{|l|c|}
\hline Technique & $\frac{P_{\text {tot }}}{U_{\max }}$ \\
\hline Numerical integration & $1.268 \cdot 10^{-3}$ \\
\hline Formula (13) applied to exact FF data & $1.268 \cdot 10^{-3}$ \\
\hline $\begin{array}{l}\text { Formula (13) applied to the FF data } \\
\text { reconstructed from PWMS measurements }\end{array}$ & $1.271 \cdot 10^{-3}$ \\
\hline
\end{tabular}

In order test the performance of the technique in more severe conditions, the excitations of the array elements have been changed for obtaining a Tschebyscheff-like behaviour with SLR $=40 \mathrm{~dB}$. The corresponding results are shown in Table 2 and, also in this case, confirm the accuracy of the proposed procedure for determining the AUT directivity from NF measurements collected via a PWMS facility.

Table 2

\begin{tabular}{|l|c|}
\hline Technique & $\frac{P_{\text {tot }}}{U_{\max }}$ \\
\hline Numerical integration & $1.744 \cdot 10^{-3}$ \\
\hline Formula (13) applied to exact FF data & $1.744 \cdot 10^{-3}$ \\
\hline $\begin{array}{l}\text { Formula (13) applied to the FF data } \\
\text { reconstructed from PWMS measurements }\end{array}$ & $1.749 \cdot 10^{-3}$ \\
\hline
\end{tabular}

\section{CONCLUSIONS}

An effective technique for the evaluation of the power radiated by an antenna from a nonredundant number of NF measurements acquired via a PWMS facility has been developed in this paper. It uses a SI formula for computing the radiated po- wer from the radiation intensity samples on the FF sphere. These samples are determined via a probe compensated NF-FF transformation. A two-dimensional OSI formula is also used for their evaluation. Such a procedure can be applied for the antenna directivity evaluation whenever the power radiated by the AUT in the backward half-space is negligible. Numerical simulations assessing its effectiveness have been shown.

\section{IN MEMORY OF PROFESSOR CATELLO SAVARESE}

Professor Catello Savarese passed away on December 27, 2007, at the age of 66, and did not see the final version of this paper. He was an eminent researcher in electromagnetic theory and applications, and was recognized as senior member of the IEEE society and member of the Electromagnetics Academy. His original scientific contributions in the development of the nonredundant sampling representations of radiated electromagnetic fields and their application to the NF-FF transformation techniques are milestones. He was also an expert and enthusiast teacher, admired by his students. Catello was a wonderful individual, mentor and friend, greatly appreciated for his huge wisdom and humanity. It was a great privilege to have known him, and to have had the opportunity to work together.

\section{REFERENCES}

[1] R. J. Stegen, The Gain-bandwidth Product of an Antenna. IEEE Trans. Antennas Propagat., vol. AP-12, pp. 505-507, July 1964.

[2] B. J. Forman, A Novel Directivity Expression for Planar Antenna Arrays. Radio Science, vol. 5, pp. 1077-1083, 1970.

[3] R. C. Hansen, Comparison of Square Array Directivity Formulas. IEEE Trans. Antennas Propagat., vol. AP-20, pp. 100-102, January 1972.

[4] C. T. Tai, C. S. Pereira, An Approximate Formula for Calculating the Directivity of an Antenna. IEEE Trans. Antennas Propagat., vol. AP-24, pp. 235-236, March 1976.

[5] A. W. Rudge et al., The Handbook of Antenna Design. Peter Peregrinus Ltd., London, UK, 1983.

[6] J. D. Kraus, Antennas. McGraw-Hill, New York, 1988.

[7] A. Safaai-Jazi, Directivity of Chebyshev Arrays with Arbitrary Element Spacing. Electronics Letters, vol. 31, pp. 772-774, May 1995.

[8] V. Schejbal, Directivity of Planar Antennas. IEEE Antennas Propagat. Magazine, vol. 41, pp. 60-65, April 1999. 
[9] D. H. Werner, D. Mulyantini, P. L. Werner, Closed Form Representation for Directivity of Nonuniformly Spaced Linear Arrays with Arbitrary Element Patterns. Electronics Letters, vol. 35, pp. 2155 -2157, December 1999.

[10] M. J. Lee, I. Song, S. Yoon, S. R. Park, Evaluation of Directivity for Planar Antenna Arrays. IEEE Antennas Propagat. Magazine, vol. 42, pp. 64-67, June 2000.

[11] J. D. Mahony, Approximate Expressions for the Directivity of a Circular Microstrip-patch Antenna. IEEE Antennas Propagat. Magazine, vol. 43, pp. 88 90, August 2001

[12] M. Dich, Accurate Determination of Antenna Directivity. IEEE Trans. Antennas Propagat., vol. 45, pp. 1502-1505, October 1997

[13] J. E. Hansen, Spherical Near-field Antenna Measurements. IEE Electromagnetic Waves Series. Peter Peregrinus Ltd, London, UK, 1998.

[14] C. Gennarelli, G. Riccio, C. Savarese, Closed Form Evaluation of the Antenna Directivity via Sam- pling Expansion. J. Electromagn. Waves Appl., vol. 16, pp. 861-870, June 2002.

[15] O. M. Bucci, G. Franceschetti, On the Spatial Bandwidth of Scattered Fields. IEEE Trans. Antennas Propagat., vol. AP-35, pp. 1445-1455, December 1987.

[16] O. M. Bucci, C. Gennarelli, C. Savarese, Representation of Electromagnetic Fields over Arbitrary Surfaces by a Finite and Non Redundant Number of Samples. IEEE Trans. Antennas Propagat., vol. 46, pp. 351-359, March 1998.

[17] F. Ferrara, C. Gennarelli, R. Guerriero, G. Riccio, C. Savarese, An Efficient Near-field to Far-field Transformation Using the Planar Wide-mesh Scanning. J. Electromagn. Waves Appl., vol. 21, pp. 341$357,2007$.

[18] D. T. Paris, W. M. Leach, Jr., E. B. Joy, Basic Theory of Probe-compensated Near-field Measurements. IEEE Trans. Antennas Propagat., vol. AP-26, pp. 373379, May 1978.

[19] J. J. Knab, The Sampling Window. IEEE Trans. Inf. Theory, vol. IT-29, pp. 157-159, January 1983

Izračun izračene snage iz rezulata mjerenja u bliskom polju dobivenih metodom uzorkovanja na planarnoj širokoj mreži. U radu je razvijena potpuna procedura za izračun snage koju zrači ispitna antena. Procedura je zasnovana na neredundantnim mjerenjima u bliskom polju na osnovi inovativnog uzorkovanja na planarnoj širokoj mreži. Metoda se može primijeniti za određivanje usmjerenosti antene u slučajevima kada je zračenje u stražnji poluprostor zanemarivo. Metoda se zasniva na uporabi izraza za izračun ukupne izračene snage preko poznavanja izračene gustoće snage uzorkovane na sferi u dalekom polju. Ti uzorci su određeni primjenom transformacije iz bliskog polja (kompeziranog zbog utjecaja mjerne sonde) $u$ daleko polje. U predloženoj metodi također je rabljena optimalna interpolacijska formula za uzorkovanje. Efikasnost predložene metode razmatrana je numeričkim simulacijama.

Ključne riječi: određivanje usmjerenosti, NF-FF transformacija, neredundantno uzorkovanje elektromagnetskog polja, planarna široka mreža za uzorkovanje

\section{AUTHORS' ADDRESSES}

Francesco D'Agostino, Associate Professor

Claudio Gennarelli, Full Professor

Rocco Guerriero, PhD

Giovanni Riccio, Associate Professor

D.I.I.I.E., Università di Salerno, via Ponte Don Melillo 84084 Fisciano (Salerno), Italy.

Catello Savarese, Full Professor (deceased)

DiT, Università di Napoli »Parthenope«

Centro Direzionale di Napoli

Isola C4, 80143 Napoli, Italy 